\title{
COMPOSIÇÃO E GEORREFERENCIAMENTO DA ARBORIZAÇÃO URBANA NO DISTRITO DE SANTA GERTRUDES, EM PATOS - PB
}

\author{
COMPOSITION AND GEOREFERENCING OF THE URBAN AFFORESTATION IN \\ THE DISTRICT OF SANTA GERTRUDES, IN PATOS - PB
}

\author{
Sérvio Túlio Pereira Justinoํㅜ, Yasmim Yathiara Gomes Araújo Morais², \\ Adna Keren de Almeida Nascimento ${ }^{3}$, Patrícia Carneiro Souto ${ }^{4}$
}

\begin{abstract}
RESUMO
O crescimento desordenado das cidades causa diversos transtornos na arborização urbana. Diante disto, o presente estudo objetivou realizar o levantamento da composição e georreferenciamento da arborização urbana do distrito de Santa Gertrudes, em Patos - PB, visando gerar informações que irão subsidiar novas ações de manejo e planejamento. Para o levantamento de dados, foi utilizado o método de inventário com caráter quantitativo para identificar as espécies existentes, analisar a relação das árvores com instalações urbanas e suas condições fitossanitárias. Foram identificadas 333 árvores, sendo $87,5 \%$ das espécies amostradas são exóticas e 12,5\% nativas. A espécie que apresentou maior frequência foi Azadirachta indica com $85,29 \%$, indicando homogeneidade na arborização urbana do distrito. Dos indivíduos levantados, apenas 10\% apresentaram conflito com a rede elétrica/telefônica e $19 \%$ dos indivíduos apresentaram raízes superficiais. Foi diagnosticado que $98 \%$ dos indivíduos apresentaram injúrias na copa. A arborização urbana do distrito de Santa Gertrudes, apresentou baixa diversidade vegetal, frequência de espécies irregulares e uso excessivo de plantas exóticas. Sugere-se que ocorra um planejamento e realização de manejo na arborização do distrito, visando a substituição gradual da espécie Azadirachta indica por espécies nativas e mais adequadas a áreas públicas.
\end{abstract}

Palavras-chave: Levantamento quantitativo; Inventário arbóreo; Fitossanidade.

\section{ABSTRACT}

The disorderly growth of cities causes various disorders in the urban forestry. Thus, the present study aimed to carry out a research on composition and georeferencing of the urban forestry from the district of Santa Gertrudes, in Patos - PB, aiming to generate information that will subsidize new management and planning actions. For date collection, the quantitative inventory method was used to identify existing species, analyze the relationship between trees and urban facilities and their phytosanitary conditions. A total of 333 trees were found, in which $87.5 \%$ were exotic and $12.5 \%$ native species. The species with the highest frequency was Azadirachta indica with $85.29 \%$, indicating homogeneity in the urban afforestation of the district. Only $10 \%$ of the trees had conflict with the utilities and $19 \%$ of the individuals showed superficial roots. It was diagnosed that $98 \%$ of the individuals presented injuries in the canopy. The urban afforestation of Santa Gertrudes district is composed by low species diversity, high frequency of irregular species and excessive use of exotic plants. It is suggested that a planning and management accomplishment take place in the afforestation of the district, aiming a gradual replacement of the specie Azadirachta indica by native species and more appropriate to public areas.

Keywords: Quantitative survey; Forest inventory; Phytosanitary.

Recebido em 14.04.2018 e aceito em 17.01.2019

1 Engenheiro Florestal. Mestrando do Programa de Pós-Graduação em Ciências Florestais da Universidade Federal de Campina Grande.Patos/PB Email: serviojustino@outlook.com

2 Engenheira Florestal. Mestranda do Programa de Pós-Graduação em Ciências Florestais da Universidade Federal Rural de Recife/PE. Email: yasmimyathiara@hotmail.com

3 Engenheira Florestal pela Universidade Federal de Campina Grande. Patos/PB. Email: Adnakeren18@hotmail.com

4 Engenheira Florestal. Professora da Unidade Acadêmica de Engenharia Florestal, Universidade Federal de Campina Grande, Campus de Patos. Email: pcarneirosouto@yahoo.com.br 


\section{INTRODUÇÃO}

Com o passar dos anos o homem vem deixando o meio rural pelo urbano, ocasionando o crescimento desordenado das cidades e irregularidades na ocupação do solo, estes fatores dificultam o planejamento adequado na implementação da arborização nesses locais (MAMEDE et al., 2014). O crescimento desordenado da população nas cidades gera diversos problemas em relação a composição arbórea nas vias e locais públicos, comprometendo a qualidade de vida dos habitantes e gerando impactos no ambiente.

$\mathrm{Na}$ implementação da arborização urbana é necessário a realização de um planejamento que leve em consideração diversos aspectos do ambiente, visando que não ocorra conflitos entre a vegetação e as estruturas urbanas. Para isso, é necessário escolher espécies adequadas e variadas para cada local, para que seja mantido a biodiversidade (PERIOTTO et al., 2016). O planejamento da arborização urbana, em algumas situações, dará subsídios para realização de atividades de manejo para sobrevivência e melhor desenvolvimentos das árvores.

A vegetação presente nas áreas urbanas proporciona benefícios na melhoria da qualidade de vida, contribui com a beleza cênica do local, proporciona abrigo e alimento à fauna da região, melhorias microclimáticas como: diminuição da velocidade dos ventos, aumento da área sombreada nas ruas e avenidas das cidades (SOUSA et al., 2013), valorização econômica de imóveis, diminuição de ruídos, dentre outros benefícios (JACKSCOTT et al., 2013).

O inventário da arborização é uma atividade que visa obter informações qualitativas e quantitativas da arborização constituinte no ambiente urbano, permitindo definir e mapear precisamente a população total das árvores presentes nas ruas, identificando a composição real da arborização, fornece informações sobre necessidades de poda, tratamentos fitossanitários e intervenções silviculturais (PAVELSKI, 2014).

Na realização do inventário, de acordo com Silva et al. (2006), os principais aspectos analisados são: a localização da árvore (rua, bairro, praça), características das árvores (espécie, porte, origem, fitossanidade) e características do meio físico (largura das ruas e passeios, presença de redes de serviços, tipo de forração na área de crescimento).

As características da árvore é um fator que deverá ser avaliado minuciosamente antes da implantação de qualquer espécie na arborização urbana. Utilizar espécies com o porte adequado e distanciamento correto, proporciona redução dos custos referentes a manutenção da árvore durante seu desenvolvimento, diminuição de conflitos que podem ocorrer entre as copas e entre as plantas com a rede elétrica (BARBOSA et al., 2015). 
É importante ressaltar que devesse escolher a metodologia adequada para cada local e o objetivo, só assim, será obtido informações adequadas sobre a arborização urbana que será utilizada em novos projetos (PAVELSKI, 2014).

O presente estudo teve como objetivo realizar o levantamento da composição e georreferenciamento da arborização urbana do distrito de Santa Gertrudes, em Patos - PB, visando gerar informações que irão subsidiar novas ações de manejo e planejamento.

\section{MATERIAL E MÉTODOS}

O estudo foi desenvolvido no distrito de Santa Gertrudes, localizado no município de Patos - Paraíba, encontra-se na mesorregião do Sertão Paraibano, com coordenadas geográficas $6^{\circ} 56^{\prime} 58,50^{\prime \prime} \mathrm{S}$ e $37^{\circ} 23^{\prime} 43,47^{\prime \prime} \mathrm{W}$, altitude de $244 \mathrm{~m}$, distante $16 \mathrm{~km}$ da sede municipal e cerca de $316 \mathrm{~km}$ da capital, João Pessoa (Figura 1). $O$ distrito de Santa Gertrudes apresenta uma população de 1.973 habitantes (IBGE, 2016).

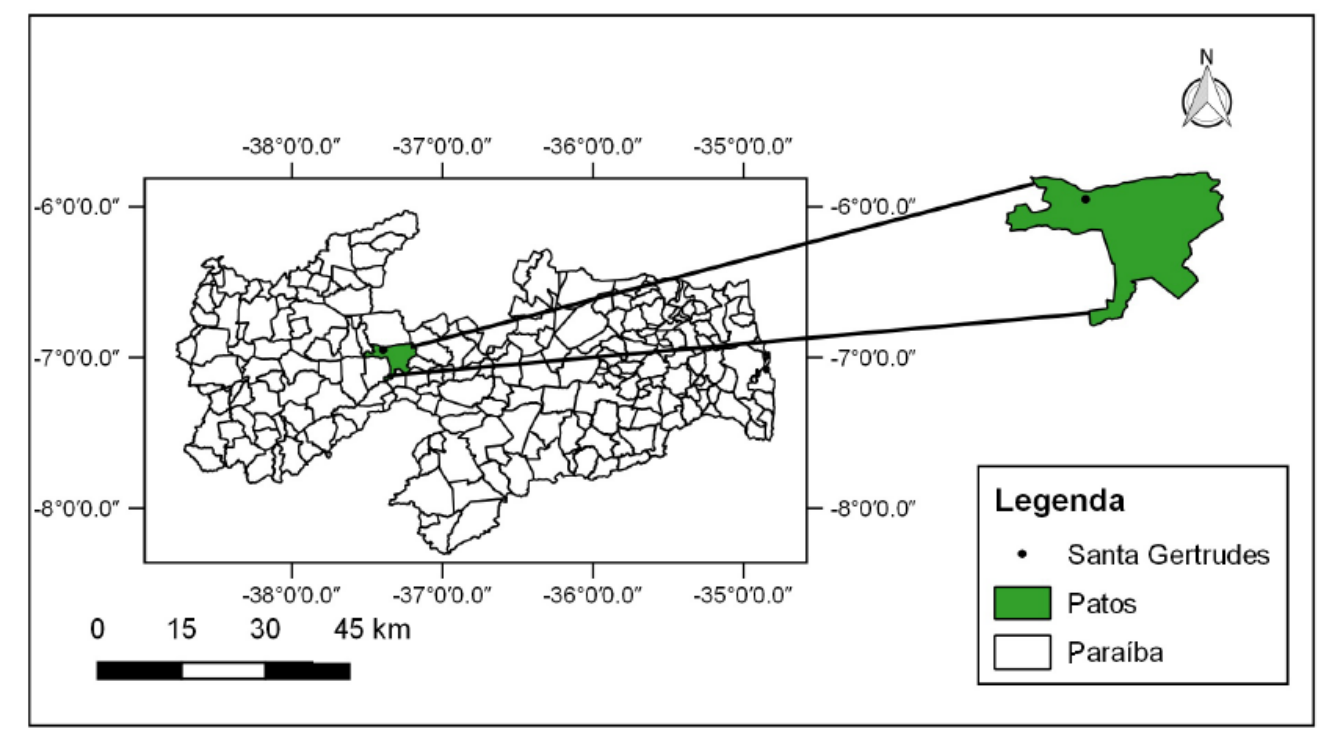

Fonte: Adaptado de IBGE (2016).

Figura 1. Mapa da Paraíba que corresponde a imagem da esquerda e localização do município de Patos a direita, onde encontra-se o distrito de Santa Gertrudes

Figure 1. Map of Paraiba that corresponds to the image and location of the municipality of Patos on the right, where the district of Santa Gertrudes is located

Segundo a classificação de Köppen (ÁLVARES et al., 2014), o clima da região é do tipo Bsh semiárido, correspondendo ao clima quente e seco, com duas estações bem definidas a estação chuvosa e a seca, com precipitação média anual de $600 \mathrm{~mm}$ e temperatura média de $28^{\circ} \mathrm{C}$. 
Os dados foram obtidos no distrito de Santa Gertrudes, entre os meses de setembro e dezembro de 2016, todas as ruas do distrito, foram percorridas juntamente com a praça pública, realizando a identificação dos indivíduos e os demais procedimentos visando completar a ficha de campo.

Para o desenvolvimento da amostragem da arborização do distrito de Santa Gertrudes foi utilizado o método de inventário com caráter quantitativo, do tipo censo, utilizando ficha de campo que foram preenchidas analisando as variáveis quantitativas e o diagnóstico do estado da arborização, como: aspectos estruturais (CAP $(\mathrm{cm})$, altura total $(\mathrm{m})$, e altura da bifurcação), condições fitossanitárias (presença ou ausência de injúrias), situação do sistema radicular (se há ocorrência ou não de afloramentos no solo) e interferências com instalações urbanas (fiação aérea e calçamento).

Para a identificação das espécies foi utilizado o método de análise visual, anotando seu nome vulgar ou científico, e quando não foi possível realizar sua identificação no campo, realizou-se o registro fotográfico, anotações morfológicas da planta, como: as características de seus órgãos vegetativos (tipo de folha, filotaxia foliar) e reprodutivos (ocorrência de flores e frutos) para facilitar a posterior identificação. A confirmação das espécies se deu através da comparação com literatura específica, os nomes científicos e as famílias de cada indivíduo foi conferido com auxílio do banco de dados presente no site Lista de Espécies da Flora do Brasil.

As árvores foram georreferenciadas com o uso de GPS Garmin, Sistema de projeção UTM datum WGS84), para a elaboração de um mapa temático da distribuição dos indivíduos, utilizou-se software QGIS 2.14.11. O GPS foi posicionado próximo ao tronco das árvores para a determinação dos pontos. Além disso, cada árvore recebeu uma nomeação numérica sequencial no aparelho GPS para especificar a sua localização. Para o levantamento dos indivíduos arbóreos foram analisadas as árvores na fase adulta, presente em calçadas e ruas.

As espécies foram classificadas quanto à origem nativas do Brasil (aquelas de origem no território brasileiro) e exóticas (espécies introduzidas fora de sua área natural de distribuição). Por fim, os dados obtidos foram copilados em planilha Excel, para que fosse realizado a análise quantitativa e a frequência relativa das espécies encontradas.

\section{RESULTADOS E DISCUSSÃO}

Foram registradas ao todo 333 árvores com o auxílio do GPS (Figura 2). Dessa forma, pôde-se observar a distribuição das árvores no distrito de Santa Gertrudes, Patos - PB, o maior número de árvores ocorreu nas ruas centrais próximas a BR e a grande ausência de árvores foi observado nas ruas periféricas. O maior número de árvores nas ruas centrais do distrito pode 
estar relacionado a sua localização em áreas onde deu início a ocupação territorial do distrito, dando início nessas regiões, de residências mais antigas, ao processo de arborização mais remoto do que as demais localizações que foram exploradas mais recentemente. Portanto, nas áreas com residências mais novas, há uma menor quantidade de árvores devido ao pouco tempo de estabelecimento das mesmas naquela localidade. A representação espacial das árvores na área de estudo, permite um maior direcionamento do planejamento da arborização urbana.

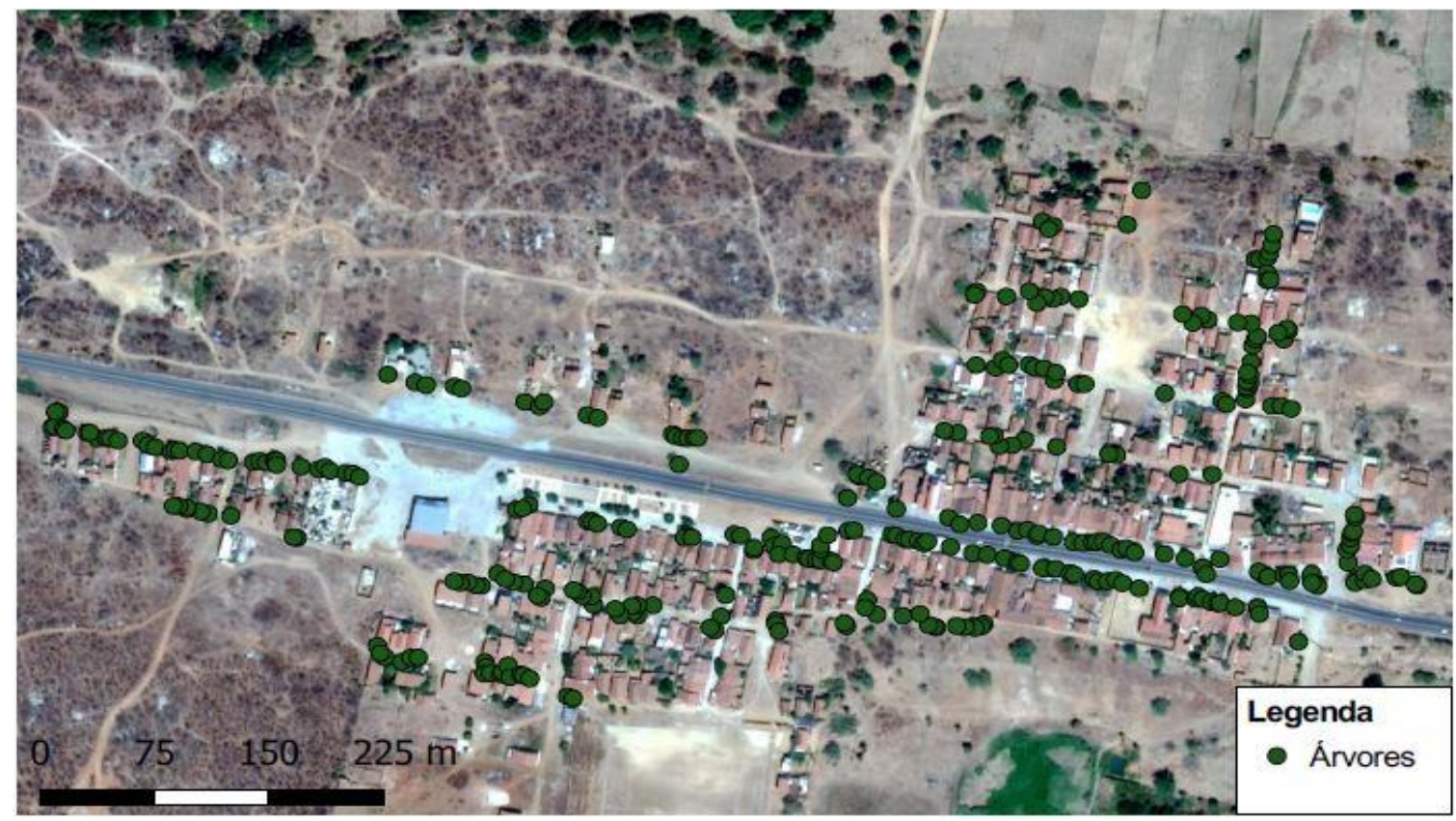

Fonte: Elaboração própria.

Figura 2. Distribuição das árvores presente no distrito de Santa Gertrudes, em Patos (PB)

Figure 2. Distribution of trees presente in the district of Santa Gertrudes, in Patos (PB)

Os 333 indivíduos arbóreos registrados em vias urbanas no distrito de Santa Gertrudes, Patos - PB, foram distribuídos em 16 espécies e 08 famílias botânicas. A família que apresentou o maior número de espécie foi a Fabaceae com seis, seguida por Anacardiaceae, Bignoniaceae e Malvaceae com duas espécies cada, as demais famílias apresentaram apenas uma espécie.

Contatou-se que $87,5 \%$ das espécies amostradas são exóticas e 12,5\% são nativas, havendo, portanto, uma grande homogeneidade na arborização urbana e evidenciando a prevalência de exóticas com relação às nativas da flora brasileira. Na arborização urbana é recomendado a utilização de espécies nativas, com ênfase nas espécies nativas regionais, pois elas proporcionam melhor interação entre a fauna e flora da região, auxiliam em atividades de educação ambiental, com evidência na conservação e preservação das espécies ameaçadas em extinção e os benefícios que elas podem trazer ao ambiente urbano (SOUSA et al., 2014). 
Tabela 1. Espécies com seus respectivos nomes científicos, nome popular, famílias, frequência (\%) e origem encontrados no distrito de Santa Gertrudes, em Patos (PB)

Table 1. Species with their respective scientific names, popular names, families, frequency (\%) and origin found in the district of Santa Gertrudes, in Patos (PB)

\begin{tabular}{|c|c|c|c|}
\hline NOME CIENTÍFICO & NOME VULGAR & ORIGEM & FR (\%) \\
\hline \multicolumn{4}{|l|}{ ANACARDIACEAE } \\
\hline Anacardium occidentale L. & Caju & Exótica & 0,30 \\
\hline Mangifera indica $\mathrm{L}$. & Manga & Exótica & 0,60 \\
\hline \multicolumn{4}{|l|}{ BIGNONIACEAE } \\
\hline Tecoma stans (L.) Juss. ex Kunth. & Ipê-mirim & Nativa & 0,30 \\
\hline $\begin{array}{l}\text { Handroanthus heptaphyllus (Vell.) Mattos } \\
\text { COMBRETACEAE }\end{array}$ & Ipê-rosa & Nativa & 0,30 \\
\hline $\begin{array}{l}\text { Terminalia catappa (L.) } \\
\text { FABACEAE }\end{array}$ & Castanhola & Exótica & 0,30 \\
\hline Delonix regia (Bojer ex Hook.) Raf. & Flamboyant & Exótica & 0,30 \\
\hline Erythrina indica picta B. \& M. & Brasileirinho & Exótica & 0,60 \\
\hline Prosopis juliflora (Sw.) DC. & Algaroba & Exótica & 5,71 \\
\hline Senna siamea (Lam.) H.S.Irwin \& Barneby & Acácia & Exótica & 0,90 \\
\hline Calliandra tweediei Hook & Esponjinha & Exótica & 0,30 \\
\hline $\begin{array}{l}\text { Enterolobium contortisiliquum (Vell.) Morong } \\
\text { MALVACEAE }\end{array}$ & Tamboril & Exótica & 0,30 \\
\hline Cola acuminata (P.Beauv) Schott \& Endl. & Cola & Exótica & 1,20 \\
\hline $\begin{array}{l}\text { Thespesia populaceae Soland. } \\
\text { MELIACEAE }\end{array}$ & Algodão-do-Pará & Exótica & 0,30 \\
\hline $\begin{array}{l}\text { Azadirachta indica A. Juss } \\
\text { MORACEAE }\end{array}$ & $\mathrm{Nim}$ & Exótica & 85,29 \\
\hline $\begin{array}{l}\text { Ficus benjamina L. } \\
\text { RUTACEAE }\end{array}$ & Fícus & Exótica & 2,40 \\
\hline Citrus limonia (L.) Osbeck & Limão & Exótica & 1,20 \\
\hline
\end{tabular}

Para Brito, Hossomi e Oliveira (2015), a arborização urbana é considerada homogênea quando há uma elevada quantidade de indivíduos de uma única espécie. Ainda de acordo com o mesmo autor, a prevalência de espécie exótica à nativa é um ponto negativo na arborização, por mudar a paisagem do local e afetar o seu ecossistema.

As espécies que apresentaram maior frequência, foram a Azadirachta indica com 85,29\%, seguida Prosopis juliflora com 5,41\%, as demais espécies tiveram uma frequência baixa. A alta frequência da Azadirachta indica na arborização urbana também foi observado em outras cidades nordestinas. Sousa et al. (2013) em trabalho realizado em Sobral - CE, verificou a maior abundância da espécie Azadirachta indica A. Juss com 51,75\%. Moraes e Machado (2014), no levantamento da arborização da cidade de Timon - MA, constatou que a espécie Azadirachta indica obteve o maior número de indivíduos, com 18,84\%.

A alta frequência dessa espécie está associada a fácil adaptação ao clima do semiárido, por apresentar um rápido crescimento e proporcionar uma sombra exuberante. Além disso, o plantio e a manutenção da arborização são realizados pelos próprios moradores e a falta de planejamento dificulta a inclusão de outras espécies nativas. Silva (2012), relata que o uso da espécie Azadirachta indica na arborização urbana deve ser evitado, pois causa 
prejuízo na infraestrutura da cidade, devido a agressão do sistema radicular e a presença de fitopatógenos específicos.

De acordo com International Society of Arboriculture (2017), os valores aceitáveis para cada espécie em uma mesma cidade não devem exceder 15\%. A partir desse percentual, observa-se os riscos associados ao desequilíbrio ambiental, como a maior suscetibilidade a doenças e ataque de pragas.

Com relação à altura total das árvores (Figura 3), observa-se que $77 \%$ dos indivíduos apresentaram altura inferior a $5 \mathrm{~m}$, enquanto que $20 \%$ encontraram-se com altura entre $5,1 \mathrm{e}$ $7,5 \mathrm{~m}$ e somente $3 \%$ apresentaram altura superior a $7,5 \mathrm{~m}$. O fato de $77 \%$ dos indivíduos estarem representados nas duas primeiras classes de altura, deve-se ao fato do recente plantio das árvores realizado no distrito. Além disso, as podas realizadas de forma incorreta também interferem na diminuição da altura das árvores, pois a maioria das podas são realizadas em épocas inadequadas pelos moradores do distrito.

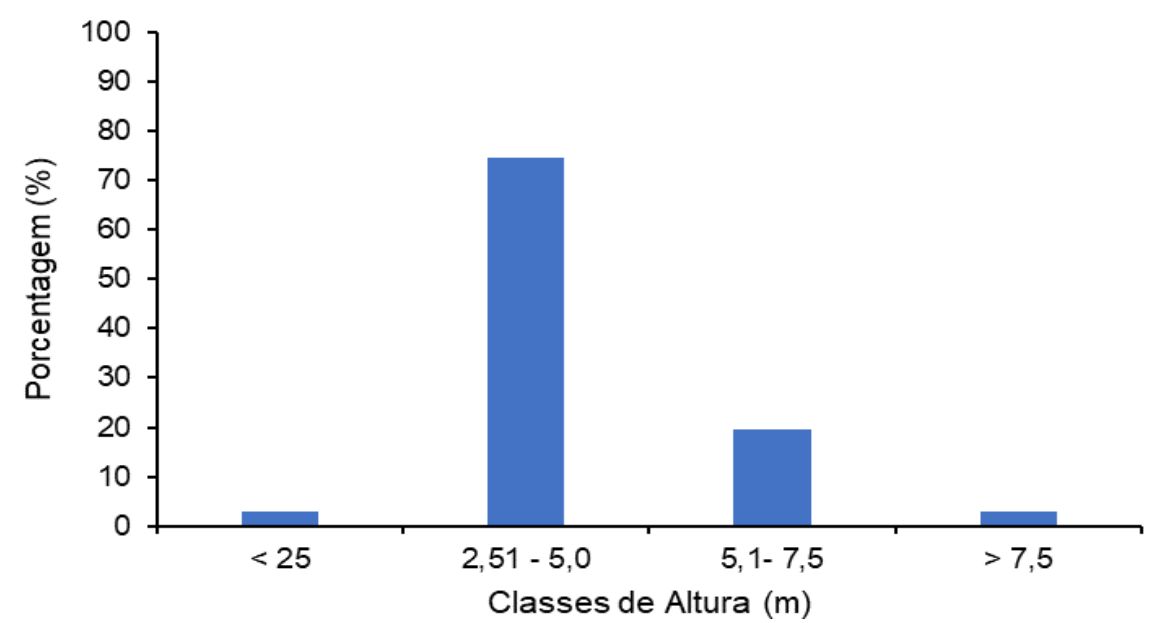

Figura 3. Classes de altura $(\mathrm{m})$ dos indivíduos existentes na arborização urbana do distrito de Santa Gertrudes, em Patos (PB)

Figure 3. Classes of height $(\mathrm{m})$ of the individuals existing in the urban afforestation of the district of Santa Gertrudes, in Patos (PB)

O grande número de indivíduos com altura inferior a $5 \mathrm{~m}$ indica que o componente arbóreo ainda está em desenvolvimento, ou seja, na fase jovem. As espécies são classificadas em pequeno porte, indivíduos com altura de até $5 \mathrm{~m}$, médio porte, 5 a $10 \mathrm{~m}$ de altura, e de grande porte, por árvores com altura superior a 10 m (BIONDI \& LEAL, 2009). Portanto, boa parte dos indivíduos do presente estudo são classificados como de pequeno porte.

Em estudo realizado por Oliveira et al. (2017), estudando o diagnóstico da arborização nas calçadas de Gurupi - TO, observou que 62,8\% dos indivíduos têm altura inferior a $6 \mathrm{~m}$. Lucena et al. (2015), em um estudo sobre a arborização em canteiros centrais na cidade de Patos - PB, verificou uma altura média de 1,6 m a 7,21 m dos indivíduos, a espécie Prosopis 
juliflora (Sw.) DC. foi a que apresentou uma maior quantidade de árvores com altura superior a $7 \mathrm{~m}$, enquanto a Mangifera indica L. foi a espécie que obteve uma menor altura, inferior a $2 \mathrm{~m}$.

A altura é um fator de vital importância na escolha da área que deverá ser introduzida uma árvore. Plantada em local inadequado, o porte da planta irá interferir no estabelecimento em que se encontra, seja na fiação elétrica, segurança, como também na mobilidade dos pedestres e veículos nas ruas e avenidas das cidades (OLIVEIRA et al., 2017).

$\mathrm{Na}$ figura 4 , observa-se que cerca de $31 \%$ dos indivíduos amostrados apresentaram DAP menor que $10 \mathrm{~cm}$, confirmando que a arborização presente no distrito é proveniente de um plantio recente. Árvores com DAP entre 10,1 e $15 \mathrm{~cm}$ corresponderam a 30\%, com DAP entre 15,1 e $20 \mathrm{~cm}$ a $21 \%$ e com DAP variando entre 20,1 e $25 \mathrm{~cm}$ e maiores que $25 \mathrm{~cm}, 12 \%$ e $7 \%$, respectivamente.

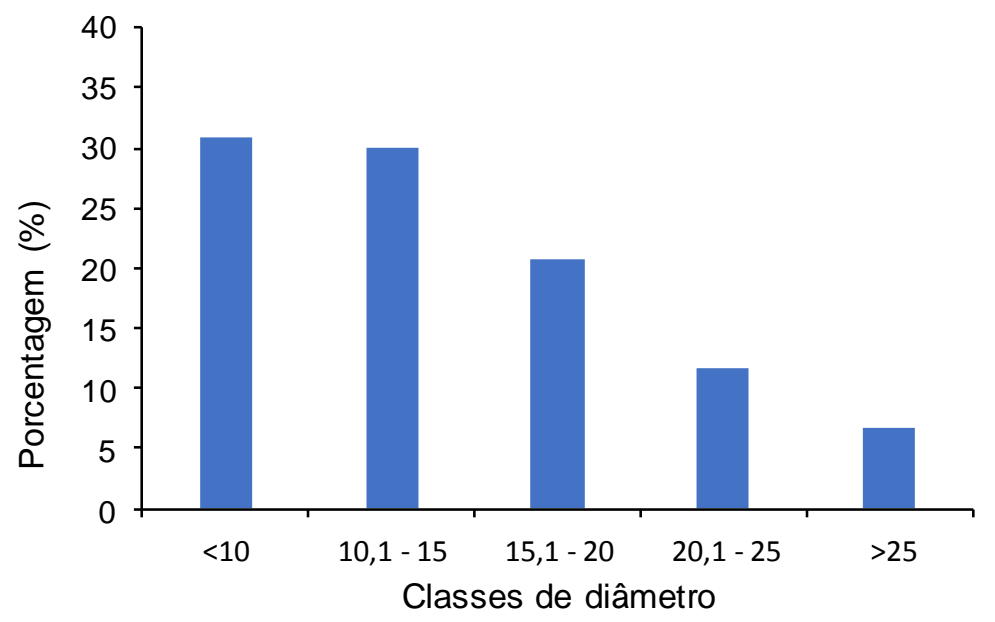

Figura 4. Classes de diâmetro (DAP) dos indivíduos existentes na arborização urbana no distrito de Santa Gertrudes, em Patos (PB)

Figure 4. Classes of diameter (DAP) of the individuals existing in the urban afforestation in the district of Santa Gertrudes, in Patos (PB)

Estes resultados são em decorrência da maioria dos indivíduos ainda serem jovens (não atingiram sua maturidade). Além disso, o baixo diâmetro dos indivíduos está relacionado também ao baixo porte dos indivíduos. A arborização do distrito se apresenta jovem, com pequenas dimensões, o que pode indicar que a oferta de benefícios ambientais como sombra, redução da temperatura, diminuição do impacto da chuva ainda não atingiu seu limite elevado.

Em relação à altura da primeira bifurcação, $71 \%$ dos indivíduos encontrados, possuem altura inferior a 1,80 m e 21\% com altura da primeira bifurcação superior a 1,80 m. De acordo com Lima Neto et al. (2010), aconselha-se que a altura da primeira bifurcação não seja inferior a 1,8 m, para que não cause problema com a tramitação dos pedestres, principalmente para aqueles com mobilidade reduzida. A alta frequência dos indivíduos com altura da primeira bifurcação inferior a 1,8 m, pode estar relacionado a falta de manejo adequado no momento do 
crescimento inicial, em decorrência do plantio ser realizado pelos próprios moradores sem a utilização de técnicas adequadas.

Dos indivíduos levantados, apenas $10 \%$ apresentaram conflito com a rede elétrica/telefônica. No entanto, uma das alternativas para que não ocorra este conflito é realizar o estudo das espécies que serão utilizados em determinado local para não prejudicar o desenvolvimento e não necessitar da realização de podas. Aqua e Muller (2014), no diagnóstico da arborização urbana de duas vias na cidade de Santa Rosa - RS, contatou que 13\% dos indivíduos apresentaram conflito com a fiação elétrica/telefônica.

Em referência ao local de plantio, o distrito de Santa Gertrudes mostrou heterogeneidade quanto as dimensões das larguras das calçadas, indicando que muitos dos problemas de pavimentação ocasionado pela planta está relacionado a esta irregularidade. Para evitar esse tipo de situação, a Prefeitura de Aracruz (2013), recomenda-se calçadas com largura de 1,5 m a 2,0 m, para árvores de pequeno porte, e de 2,0 m a 2,40 m, para espécie com altura superior a $8 \mathrm{~m}$.

Quanto a condição das raízes, 19\% dos indivíduos apresentaram raízes superficiais. As árvores com raízes que se desenvolveram na superfície do solo, podem estar relacionadas a profundidade do berço no momento do plantio, além disso, a compactação do solo é prejudicial ao desenvolvimento das raízes. Em estudo sobre arborização urbana de 25 vias públicas da cidade de Aracaju - SE, Santos et al. (2015), observou que 33\% dos indivíduos levantados apresentaram raízes superficiais, as espécies Ficus benjamina L., Prosopis juliflora (Sw.) DC. e Terminalia catappa Linn apresentaram uma maior quantidade de indivíduos a ocasionarem problemas nas áreas presente.

Em relação ao aspecto fitossanitário, foi diagnosticado que $98 \%$ dos indivíduos apresentaram injúrias na copa sendo mais ocorrente nas áreas com uma maior movimentação da comunidade, devido muitas árvores serem utilizadas como suporte para ornamentação, o que demanda o uso de instrumentos de fixação dos adornos, como pregos e grampos, causando sérios danos as árvores. A alta incidência de injúrias está relacionada aos tipos de podas inadequadas, realizado pelos próprios moradores. A ocorrência dessas injúrias favorece a proliferação de pragas e doenças, podendo levar a árvore a morte. Outro aspecto observado, foi a presença de pregos, arames e cordões nos troncos das árvores, que também favorece o ataque dos fungos e insetos prejudicando o desenvolvimento da árvore. Souza et al. (2014), no inventário da arborização do centro da cidade de São Joaquim - SC, constatou que $41 \%$ das árvores possuíam algum tipo de injúrias no tronco ou na copa, decorrente as técnicas de podas utilizadas e aos atos de vandalismo da população. 


\section{CONCLUSÕES}

A arborização urbana do distrito de Santa Gertrudes, apresentou baixa diversidade vegetal, frequência de espécies irregulares e uso excessivo de plantas exóticas. A maior frequência foi de Azadiracta indica, devido a fácil adaptação ao clima do semiárido, por apresentar um rápido crescimento e proporcionar uma sombra exuberante.

Com base nas características qualitativas avaliadas, foi diagnosticado que a vegetação nas áreas de estudo estava com condições fitossanitárias precária, devido a poda drástica, a presença de patógenos e injúrias no tronco, indicando um manejo inadequado realizado pela própria população.

Sugere-se um planejamento na implantação (escolha da espécie, local, espaçamento, plantio e manutenção (poda e troca de indivíduos), e a realização de manejo na arborização do distrito de Santa Gertrudes, abrangendo principalmente o acréscimo das áreas livres e a substituição gradual ou a diminuição de frequência de Azadiracta indica por espécies nativas e mais adequadas a áreas públicas, de maneira que esta espécie exótica não afete o ecossistema urbano e nem traga problemas na pavimentação do distrito.

Devido à elevada prática de ações errôneas na arborização urbana do distrito, seja na implantação, manejo e atos de vandalismo, recomenda-se programas de educação ambiental para a população de Santa Gertrudes no planejamento da arborização de ruas.

\section{REFERÊNCIAS}

ALVARES, C. A.; STAPE, J. L.; SENTELHAS, P. C.; MORAES, J. L.; GONÇALVES, J. L. M.; Gerd Sparovek. Köppen's climate classification map for Brazil. Meteorologische Zeitschrift, Stuttgart, v. 22, n. 6, p.711 - 728, 2014.

AQUA, M. D.; MULLER, N. T. G. Diagnóstico da arborização urbana de duas vias na cidade de Santa Rosa - RS. Revista da Sociedade Brasileira de Arborização Urbana, Piracicaba SP, v. 9, n. 3, p. $141-155,2014$.

BARBosA, R. P.; PORTELA, M. G. T.; MACHADO, R. R. B.; SÁ. A. S. Arborização da avenida deputado Ulisses Guimarães, bairro Promorar, zona sul de Teresina - PI. Revista da Sociedade Brasileira de Arborização Urbana, Piracicaba - SP, v. 10, n. 2, p. 78 - 89, 2015.

BIONDI, D.; LEAL, L. Avaliação de espécies plantadas experimentalmente na arborização de ruas da cidade de Curitiba - PR. Revista da Sociedade Brasileira de Arborização Urbana, Piracicaba - SP, v. 4, n. 4, p. 79-99, 2009.

BRITO, L.; HOSSOMI, S. T.; OLIVEIRA, W. L. Espécies exóticas na arborização viária do município de Rancharia - SP. Periódico Técnico e Científico Cidades Verdes, Prudente-SP, v. 3, n. 6 , p. $69-74,2015$. 
INSTITUTO BRASILEIRO DE GEOGRAFIA E ESTATÍSTICA - IBGE. Censo Demográfico. 2016. Disponível em: <https://cidades.ibge.gov.br/brasil/pb/patos/panorama>. Acesso em: 08 de março de 2018.

INTERNATIONAL SOCIETY OF ARBORICULTURE - ISA. Disponível em: <http://www.isaarbor.com/>. Acesso em: 10 de setembro de 2017.

JACK-SCOTT, E.; PIANA, M.; TROXEL, B.; MURPHY-DUNNING, C.; ASHTON, M. S. Stewardship success: how community group dynamics affect urban street tree survival and growth. Arboriculture and Urban Forestry, Champaign, v. 39, n. 4, p. 189-196, jul. 2013.

LIMA NETO, E. M. de.; BARDELLI-DA-SILVA, M. Y.; SILVA, A. R.; BIONDI, D. Arborização de ruas e acessibilidade no bairro centro de Curitiba-PR. Revista Sociedade Brasileira de Arborização Urbana, Piracicaba - SP, v. 5, n. 4, p. 40 - 56, 2010.

LUCENA, J. N., SOUTO, P. C.; CAMAÑO, J. D. Z., SOUTO, J. S.; SOUTO, L. S. Arborização em canteiros centrais na cidade de Patos, Paraíba. Revista Verde de Agroecologia e Desenvolvimento Sustentável, Pombal - PB, v. 10, n. 4, p. 20 - 26, 2015.

MAMEDE, J. S. dos S.; SOUZA, F. F. de; SANTOS, A. F. A.; DUTRA, R. M. C.; RONDON NETO, R. M. Levantamento quali-quantitativo de espécies arbóreas e arbustivas na arborização urbana do município de Paranaíta, Mato Grosso. Revista Biodiversidade, Rondonópolis - MT, v. 13, n. 2, p; 56 - 63, 2014.

MORAES, L. A.; MACHADO, R. R. B. A arborização urbana do município de Timon/MA: inventário, diversidade e diagnóstico quali-quantativo. Revista da Sociedade Brasileira de Arborização Urbana, Piracicaba - SP, v. 9, n. 4, p. 80 - 98, 2014.

OLIVEIRA, L. M.; SANTOS, A. F.; Diagnóstico da arborização nas calçadas de Gurupi -TO. Revista da Sociedade Brasileira de Arborização Urbana, Piracicaba - SP, v. 12, n. 1, p. 105 $-121,2017$.

PAVELSKI, L. G. Análise quali-quantitativa da arborização existente no Parque Central José Rossi Adami, no município de Caçador, SC. 2014. 57 p. Dissertação (Mestrado em Gestão Florestal) - Universidade Federal do Paraná, Curitiba - PR, 2014.

PERIOTTO, F.; PITUCO, M. M.; HELMANN, A. C.; SANTOS, T. O. dos; BORTOLOTTI, S. L. Análise da arborização urbana no município de Medianeira, Paraná. Revista da Sociedade Brasileira de Arborização Urbana, Piracicaba - SP, v. 11, n. 2, p. 59 - 74, 2016.

PREFEITURA DE ARACRUZ. Manual de recomendações técnicas para projetos de arborização urbana e procedimento de poda. Secretaria Municipal do Meio Ambiente. Aracruz, p. $7-8.2013$

SANTOS, C. Z. A.; FERREIRA, R. A.; SANTOS, L. R.; SANTOS, L. I.; GOMES, S. H.; GRAÇA, D. A. S. Análise qualitativa da arborização urbana de 25 vias públicas da cidade de Aracaju SE. Ciência Florestal, Santa Maria, v. 25, n. 3, p. 751 - 763, 2015.

SILVA, A. G.; GONÇALVES, W.; LEITE, H. G.; SANTOS, E. Comparação de três métodos de obtenção de dados para avaliação quali-quantitativa da arborização viária, em Belo Horizonte MG. Revista da Sociedade Brasileira de Arborização Urbana, Piracicaba - SP, v. 1, n. 1, p. $31-44,2006$. 
SILVA, R. N. Caracterização e análise quali-quantitativa da arborização em praças da área central da cidade de Arapiraca, AL. Revista da Sociedade Brasileira de Arborização Urbana, Piracicaba - SP, v. 7, n. 2, p. $102-115,2012$.

SOUSA, L. M.; FIGUEIRÊDO, M. F.; BRAGA, P. E. T. Levantamento quali- quantitativo da arborização urbana do distrito de Rafael arruda, sobral, CE. Revista da Sociedade Brasileira de Arborização Urbana, Piracicaba - SP, v. 8, n. 3, p. 118 - 129, 2013.

SOUSA, R. de C.; AGUIAR, O. T. de; SILVA, L. T. A. da; SILVA, L. A.; MARRA, R. C. Avaliação quali-quantitativa da arborização na praça Agostinho Nohama, bairro Lauzane Paulista, São Paulo - SP. Revista da Sociedade Brasileira de Arborização Urbana, Piracicaba - SP, v. 9, n. 1, p. $92-107,2014$.

SOUZA, P. F. de.; BOURSCHEID, C. B.; POMPEO, P. N.; STANG, M. B.; MANFROI, J.; RODRIGUES, M. D. S.; SILVA. A. C. da.; HIGUCHI, P. Inventário e recomendações para a arborização do centro da cidade de São Joaquim, SC. Revista da Sociedade Brasileira de Arborização Urbana, Piracicaba - SP, v. 9, n. 4, p. 99 - 112, 2014. 